\title{
EFFECT OF AIR-FUEL RATIO ON TEMPERATURE DISTRIBUTION AND POLLUTANTS FOR BIOGAS MILD COMBUSTION
}

\author{
M.M. Noor ${ }^{1,2}$, Andrew P. Wandel ${ }^{1}$ and Talal Yusaf ${ }^{3}$ \\ ${ }^{1}$ Computational Engineering and Science Research Centre, School of Mechanical and \\ Electrical Engineering, University of Southern Queensland (USQ), Australia \\ ${ }^{2}$ Faculty of Mechanical Engineering, Universiti Malaysia Pahang (UMP), \\ 26600 Pekan, Pahang, Malaysia \\ ${ }^{3}$ National Centre for Engineering in Agriculture, USQ, Australia \\ Email: muhamad@ump.edu.my \\ Phone: +6094246255; Fax: +6094246222
}

\begin{abstract}
This paper examines the effect of air-fuel ratio for Moderate or Intense Low oxygen Dilution (MILD) combustion using a bluff-body burner. Exhaust gas recirculation was used to dilute the oxidizer stream prior to the combustion chamber. A low-calorie biogas fuel which consists of $60 \%$ methane and $40 \%$ carbon dioxide were used in the simulations using a Reynolds-averaged Navier-Stokes model with the realizable $k-\varepsilon$ turbulence model. The chamber temperature distribution was found to be in small ranges and almost homogeneously distributed, verifying that MILD conditions were attained. The performance was evaluated based on the level of pollutants (Unburned hydrocarbons (UHC) and carbon-mono oxide (CO)) produced and measured in the exhaust gas. Slightly lean conditions produced negligible pollutants with some excess oxygen measured in the exhaust gas. Under rich conditions, UHC and $\mathrm{CO}$ were produced, but when synthetic air containing oxygen with a mole fraction of $7 \%$ was used as the oxidizer instead of ordinary air, these levels were significantly reduced.
\end{abstract}

Keywords: MILD combustion; biogas; air-fuel ratio; exhaust gas recirculation; unburned hydrocarbon.

\section{INTRODUCTION}

Fuel efficiency and reduced pollutants are demanded by the combustion industry due to the fuel cost and environmental regulations $[1,2]$. Combustion is predicted to be the most important way of generating future energy [1, 3-6]. Fuel depletion and emission is the main issue to cater this energy need [7, 8]. Combustion technology with higher thermal efficiency and biogas fuels are possible long term solutions. A new combustion process is able to contribute to the increase of combustion thermal efficiency and reduce of the emissions. MILD combustion produces higher thermal efficiency due to re-cycling of Exhaust Gas by using exhaust gas recirculation (EGR) [7, 9-12]. Others call it flameless oxidation (FLOX) [13, 14], High-Temperature Air Combustion (HiTAC) [15, 16] and Colourless Distributed Combustion (CDC) [17, 18]. It emits low nitrogen oxides and carbon monoxide pollutant emissions [2, 19-24]. By recycle the waste heat of exhaust gases, the thermal efficiency of MILD combustion can increase by $30 \%$, while reducing oxide of nitrogen emissions by $50 \%$ [16]. The cycle of carbon dioxide is in 
close loop when emitted carbon dioxide from the combustion process will be re-used by the source of biogas when using the combustion is biogas (Low Calorific Value (LCV)) as a fuel $[8,25,26]$.

In order to create a laboratory experiment's practical synthetic biogas, a mixture of $60 \%$ methane and $40 \%$ carbon dioxide was used. This ratio of synthetics biogas was also used by other researchers [27-29]. The biogas produce by feedstock normally consists of about $55 \%$ to $65 \%$ of methane, $30 \%$ to $40 \%$ carbon dioxide and $5 \%$ nitrogen. The mixture composition, measured by lambda (the Air-Fuel Ratio divided by the stoichiometric AFR) is an important parameter to indicate the combustion quality. The effect of AFR on the combustion efficiency has been studied for MILD combustion [30, 31]. The performance of combustion is very dependence to lambda, with the optimum efficiency is near stoichiometry condition. High lambda will be too lean combustion and low lambda will result in unburned hydrocarbons (UHC). Due to fuel consumption, the industrial applications always use leaner combustion compared to rich combustion. The MILD combustion required lower oxygen in oxidant stream and higher temperature of the reactant mixture. Exhaust gas recirculation (EGR) has previously been used for MILD combustion $[11,15]$. In this case, the combustion chamber needs to be enclosed in order to collect the exhaust gas and mixed with the supply fresh air. MILD combustion can be achieved when the oxygen level is between 3-13\% [32]. The purpose of this paper is to study the combustion lambda and the pollutions for open furnace MILD combustion.

\section{SIMULATION SETUP}

Numerical simulations are commonly used to solved many engineering problem due to cost effective, quicker and reliable solution. Many researchers have used numerical simulations to study MILD and flameless combustion [33-35]. The open chamber studied here (Figure 1) is $1.0 \mathrm{~m}$ high and $0.6 \mathrm{~m}$ wide and was simulated using FLUENT 14.5. The burner's data is shown in Table 1.

Table 1. Typical data for burner and combustion chamber.

\begin{tabular}{ll}
\hline \multicolumn{1}{c}{ Item } & \multicolumn{1}{c}{ Data } \\
\hline Fuel & 60\% methane and 40\% carbon dioxide \\
Oxidizers & Atmospheric and synthetic air \\
Fuel / air inlet & $0.78 \mathrm{~mm}^{2} / 1570 \mathrm{~mm}^{2}$ \\
Chamber size & Diameter $600 \mathrm{~mm}$, Height $1000 \mathrm{~mm}$ \\
EGR & 4 EGR pipe, each with 50 mm diameter \\
\hline
\end{tabular}

A bluff body was used to stabilize the flame. The fuel nozzle was in the middle with a diameter of $1 \mathrm{~mm}$ and an annular air nozzle with an opening size of $1,570 \mathrm{~mm}^{2}$; the bluff body diameter $\left(D_{b}\right)$ was $40 \mathrm{~mm}$ and four EGR pipes were used. In this work, the RANS equations together with the realizable $k-\varepsilon$ turbulence model [36] were solved, as used previously for MILD combustion [37]. The discrete ordinate radiation model [38] and absorption coefficient of weighted sum of gray gas (WSGGM) model were used $[39,40]$. The discrete ordinates radiation model solves the radiative transfer equation for a finite number of discrete solid angles in Cartesian system. The combustion was modelled using non premixed combustion with non-adiabatic flame temperature. The chemical model used is the equilibrium chemistry model couple with the probability 
density function (PDF) model, as used for similar modelling in Refs. [14, 41]. In the current work, 16 species were solved at 56 grid points in mixture fraction space for a range of enthalpies to yield 24,472 potential compositions in the PDF look-up table. The temperature of the wall was set at $300 \mathrm{~K}$. All the governing equations were solved using the second order upwind discretization scheme for improved accuracy. The velocitypressure coupled solver was used with the gradient least square cell based algorithm and presto pressure discretization scheme. A tetrahedral mesh with 897,703 elements was used.

The fuel supply had a $10 \mathrm{~mm}$ diameter which tapered down to the nozzle diameter at the entrance to the combustion chamber. Air was injected through four supply pipes of $10 \mathrm{~mm}$ diameter each at the sides of the EGR. There are two driving forces for EGR: the percentage of damper opening for the exhaust, which encourages flow to be redirected into the EGR inlets; and the fresh oxidant supply jet near the end of each EGR pipe (on the side injected into the bottom part of the EGR pipe) which induces flow through the pipes. The flue gas flow through the EGR pipe for the current results is calculated at $35.7 \%$ with the balance (controlled by a butterfly valve) allowed to flow out through the exhaust pipe on top of the burner (Figure 1). The fresh air supply then mixed with the exhaust gas (that flows downward) from the EGR pipe at the mixing area. The fuel for this burner is biogas or low calorific value gas. The biogas was produced by mixing methane and carbon dioxide. In the authors' earlier paper [31], a different LCV composition was used. In this paper, two gases are mixed: methane and carbon dioxide (Table 2). Table 2 also shows a sample composition of biogas, where there are similar levels of fuel and diluents to the syngas studied here.
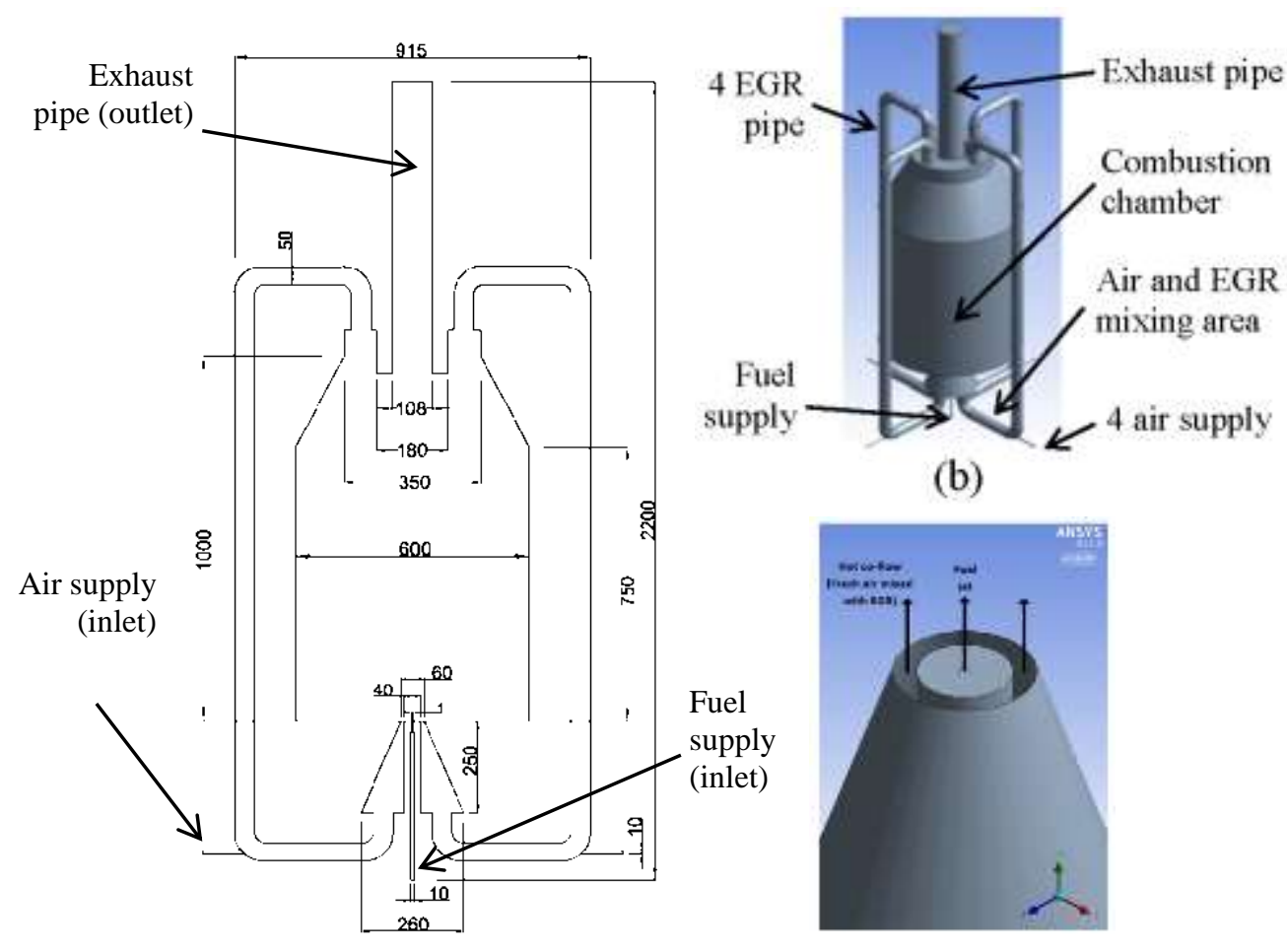

(b)

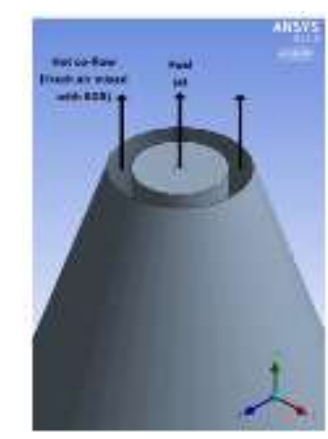

Figure 1. Burner model (a) 2D dimension in mm (b) 3D burner geometry with boundary conditions (c) air and fuel nozzle geometry and combustion flow direction. 
Table 2. LCV gas composition in mole fraction .

\begin{tabular}{lccc}
\hline \multicolumn{1}{c}{$\mathrm{Gas}$} & Syngas & Biogas & LCV gas [31] \\
\hline Methane $\left(\mathrm{CH}_{4}\right)$ & 0.60 & 0.600 & 0.5344 \\
Hydrogen $\left(\mathrm{H}_{2}\right)$ & 0.00 & 0.000 & 0.3000 \\
Carbon dioxide $\left(\mathrm{CO}_{2}\right)$ & 0.40 & 0.350 & 0.1336 \\
Nitrogen $\left(\mathrm{N}_{2}\right)$ & 0.00 & 0.030 & 0.0130 \\
Ethane $\left(\mathrm{C}_{2} \mathrm{H}_{6}\right)$ & 0.00 & 0.017 & 0.0170 \\
Propane $\left(\mathrm{C}_{3} \mathrm{H}_{8}\right)$ & 0.00 & 0.002 & 0.0010 \\
Butane $\left(\mathrm{C}_{4} \mathrm{H}_{10}\right)$ & 0.00 & 0.001 & 0.0010 \\
\hline
\end{tabular}

The oxygen in the oxidizer stream will be diluted by EGR to the required level. In addition, synthetic air (with $3 \%$ to $15 \%$ oxygen mole fraction mixed with nitrogen) is compared with atmospheric air as the oxidizer stream. The lambda and air velocity used in this study range from 0.2 to 5.0 and 8 to $15 \mathrm{~m} / \mathrm{s}$ respectively.

\section{RESULTS AND DISCUSSION}

The results of the simulations are discussed with the main purpose to measure and analyze the lambda of the biogas combustion. A grid independence study was performed to confirm the accuracy of the mesh used in the current simulations. To conduct the parametric study, lambda was altered by varying the air and fuel supply rates. This was done for a number of different values of oxygen mole fraction in the air supply. As a preliminary study to confirm that the behaviour of the syngas is representative of a real biogas, the unburned $\mathrm{CH}_{4}$ mole fraction for high speed flow is compared in Figure 2. While the syngas slightly overestimates the values for rich conditions, the same trend to negligible amounts for stoichiometric and lean conditions is reproduced, so it can be concluded that the syngas is reasonably representative of the biogas.

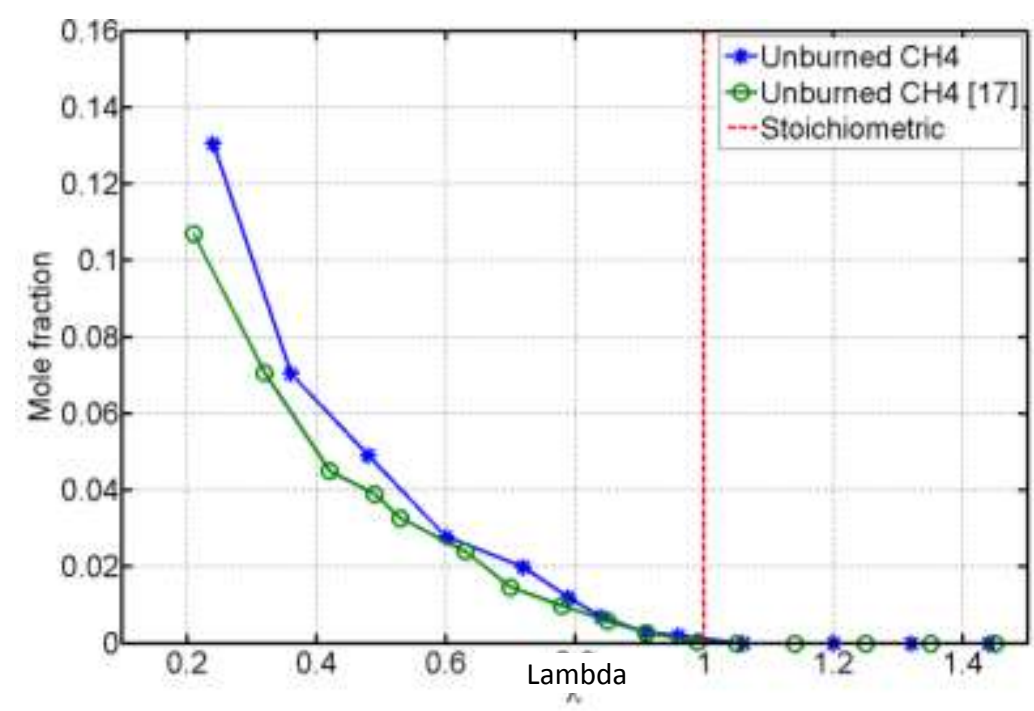

Figure 2. Unburned $\mathrm{CH}_{4}$ with atmospheric air with air inlet $20-100 \mathrm{~m} / \mathrm{s}$. Syngas, closed symbols; biogas [31], open symbols. 
Figure 3 demonstrates the effects of UHC levels in the current system. In Figure 3(a), the mixing of the air supply with the EGR produces chemical reactions prior to the combustion chamber. Figure 3(b) shows a desirable operating condition with homogeneous temperature, causing the mixing of EGR and air to merely preheat the fresh supplied air. The combustion process achieves the MILD combustion state: the majority of the chamber's temperature distribution is uniformly distributed from $822 \mathrm{~K}$ to $844 \mathrm{~K}$ which is a variation of $2.7 \%$. The ranges are considered to be in a uniformly small range. This is in agreement with the condition that the MILD combustion regime is achieved when the temperature distribution ranges by less than 23\% (Figure 4) [16]. The highest temperature is observed slightly above the wake of the bluff-body since this is the primary mixing zone for the fuel and oxidizer. The mixture in this region is close to stoichiometric conditions, so it is inevitable that it is relatively hot. Also, this is adjacent to the recirculation region of the fuel with some of the oxidizer stream, so the increased residence time with reduced dilution causes the higher temperature. Once this mixture is further diluted with the rest of the oxidizer stream, the MILD conditions are able to dominate and reduce the temperature to the almost-constant levels detected further downstream. When there are sufficiently-high inlet velocities and sufficiently diluted oxygen, MILD conditions will develop in the chamber and the primary mixing zone is small thereby releasing only a fraction of the total heat.

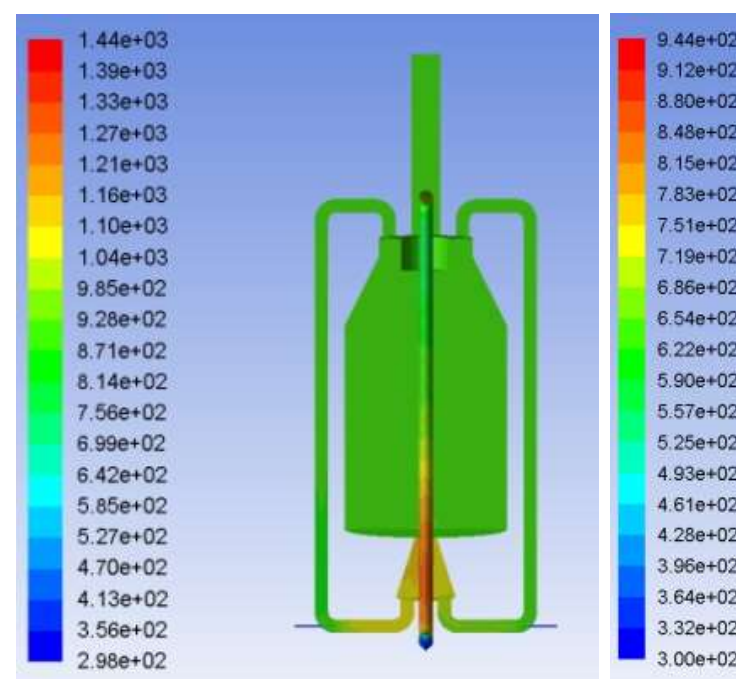

(a)

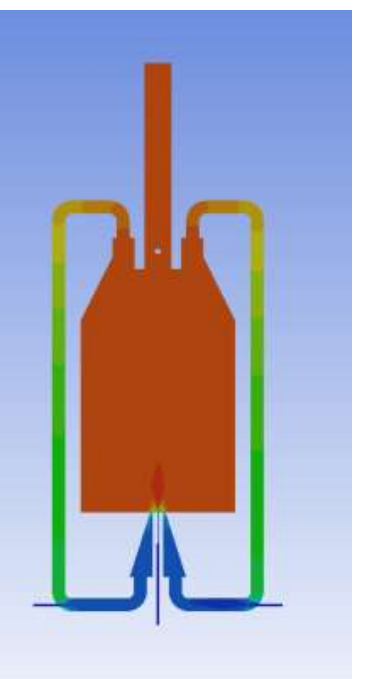

(b)

Figure 3. Temperature contours. (a) Unwanted burning between EGR and oxidizer before combustion chamber for $21 \%$ oxygen mole fraction with $10.0 \mathrm{~m} / \mathrm{s}$ air inlet and lambda of 0.43 . (b) Proper MILD combustion for 7\% oxygen mole fraction with 10.0 $\mathrm{m} / \mathrm{s}$ air inlet and lambda of 0.78 .

The open furnace has been proved by the flow of streamline from air supply pipe to the exhausts opening on the top as shown in Figure 5. Figure 5(a) shows the oxidant flow smoothly from the supply inlet and exhaust opening. This was supported by Figure 5(b) that shows the velocity magnitude for the flow. The maximum and average temperatures inside the chamber and the air mixing temperature are plotted in Figure 6 for the lambda of 0.78 . The average and maximum chamber temperature were almost identical at $3 \%$ inlet oxygen mole fraction with the difference increasing with inlet oxygen mole fraction. At $3 \%$ inlet oxygen, the temperature distribution and heat 
produced was homogeneously uniform throughout the chamber, becoming less uniform when the oxygen mole fraction increases. The ratio of maximum-to-average temperature was less than the required 23\% temperature ratio for a MILD chamber for oxygen mole fractions less than $11 \%$. The $13 \%$ oxygen mole fraction had a temperature ratio of about $22.7 \%$ so is in the MILD regime and corresponds to the greatest increase in average temperature from the initial (air mixing) value. Beyond 13\% oxygen, the efficiency decreases (lower increases in average temperature) owing to the conventional flame that is produced.

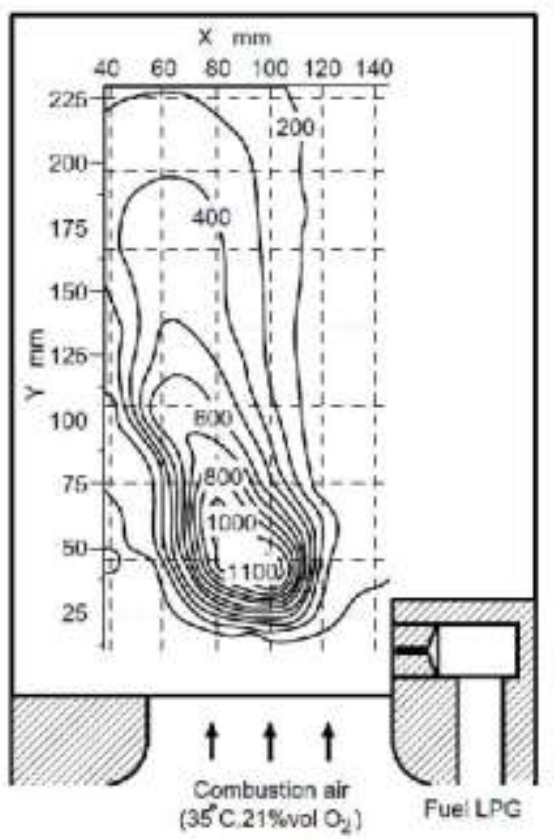

(a)

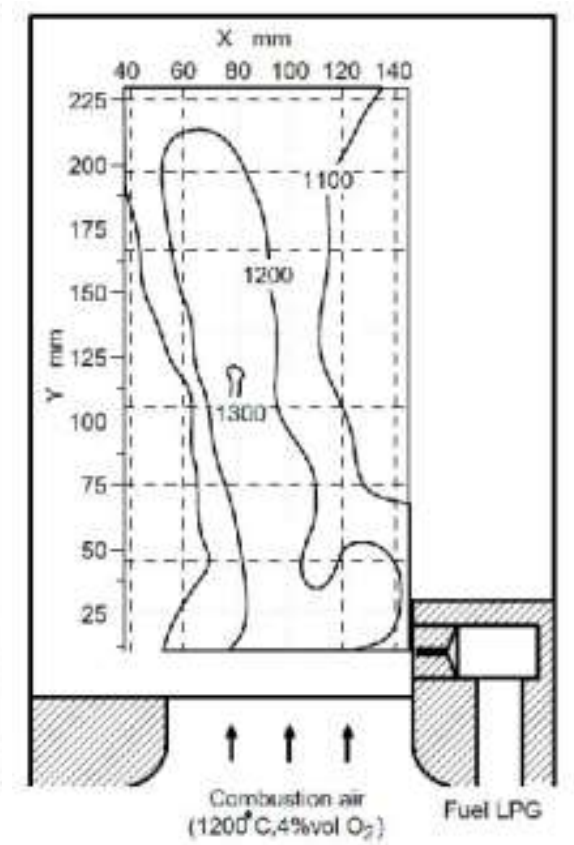

(b)

Figure 4. Combustion temperature distribution (a) convensional combustion: room temperature oxidant with $21 \%$ oxygen mole fraction (b) MILD combustion: preheat oxidant with $4 \%$ oxygen mole fraction [16].

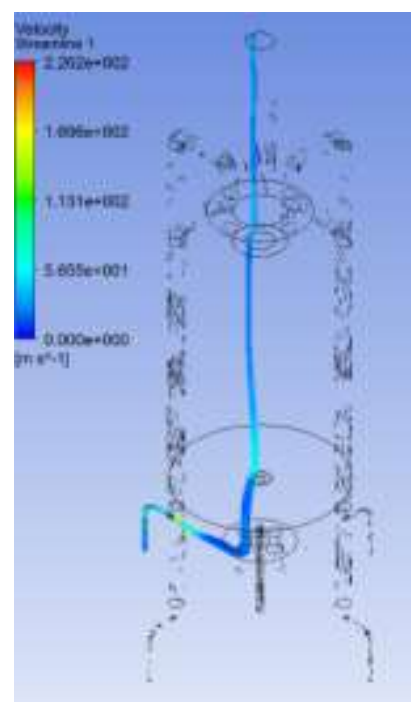

(a)
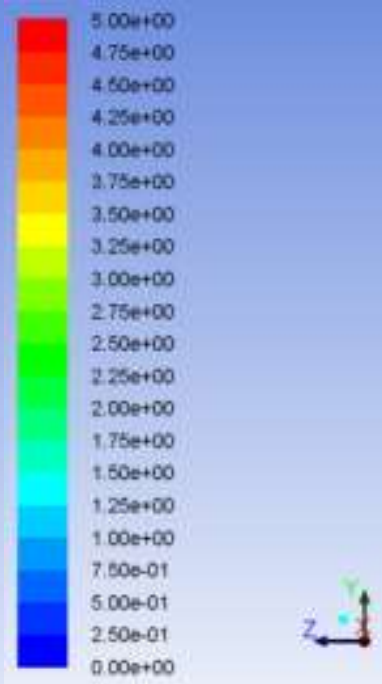

(b)

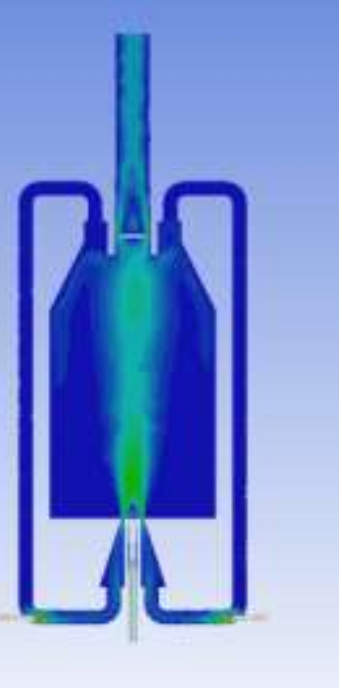

Figure 5. The flow inside the combustion chamber (a) vector plot (b) the velocity magnitude. 


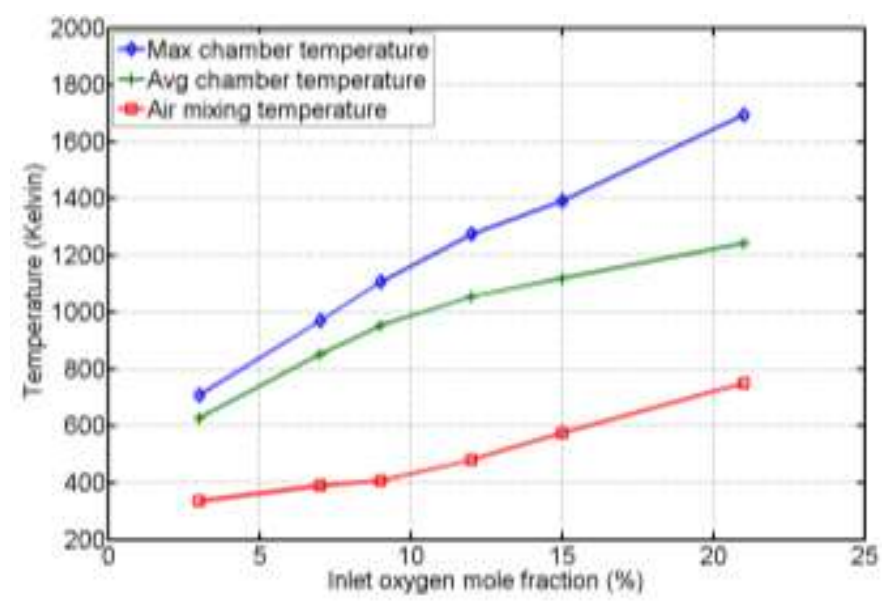

Figure 6. Maximum and average chamber and air mixing temperatures at lambda $=$ 0.78 .

Figure 7 shows the axial location on the combustion chamber with the marking of A-A to F-F for the temperature measurement area used (and planned for the experimental work) in Figure 8. This variation in maximum and average temperatures with different inlet oxygen mole fractions is due to the lack of uniformity near the bluff body (Figure 8: note that the same scale is used). For 3\% oxygen, the extra load of nitrogen keeps the temperature rise along the fuel jet to a minimum, while by $15 \%$ there is a significant variation, but this is still in MILD conditions (as noted in Table 3). For $21 \%$ oxygen, the ratio of minimum-maximum temperature was above $23 \%$ which is caused by the temperature rise almost exclusively being contained within $r / \mathrm{D}_{\mathrm{b}}<2$. In this study, the wall temperature was set at room temperature, so the temperature profiles are not as uniform as for a higher wall temperature of 1300K [41], with the largest variations occurring near the bluff body (Station A-A). The effect of air supply velocity on the flame temperature was very clear. Comparing the three different air supply velocities $(8 \mathrm{~m} / \mathrm{s}, 10 \mathrm{~m} / \mathrm{s}$ and $15 \mathrm{~m} / \mathrm{s}$, refer to Supplementary Material) at the same oxygen mole fraction of $3 \%$, the higher the air supply velocity, the higher the temperature of the flame.

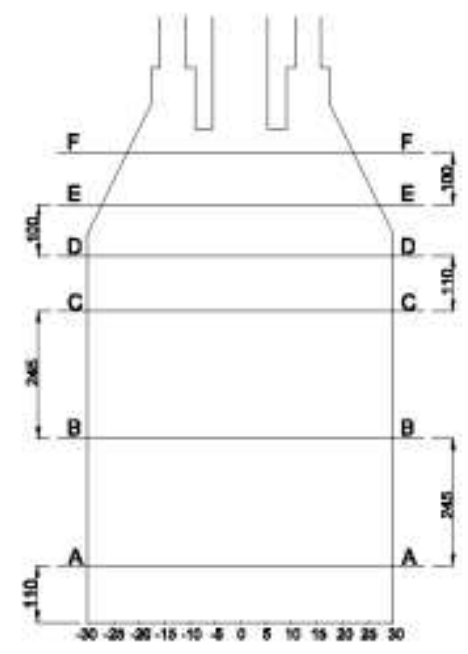

Figure 7. Chamber axial location for the temperature profile. Downstream distance from injection location, $\mathrm{x} / \mathrm{D}_{\mathrm{b}}$ : Station $\mathrm{A}-\mathrm{A}=2.8, \mathrm{~B}-\mathrm{B}=8.9, \mathrm{C}-\mathrm{C}=15.0, \mathrm{D}-\mathrm{D}=17.8, \mathrm{E}-\mathrm{E}=$ $20.3, \mathrm{~F}-\mathrm{F}=22.8$. 


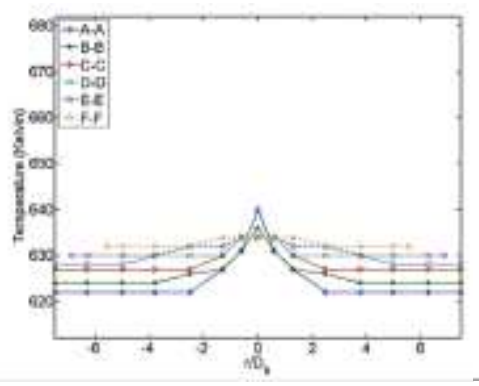

(a)

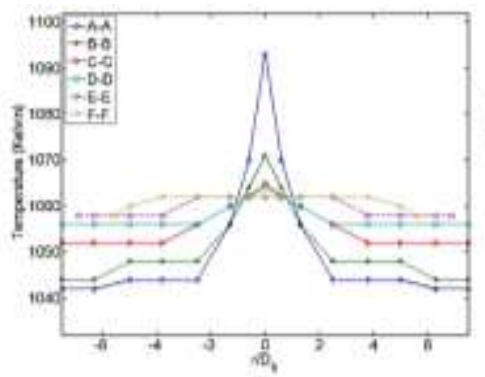

(d)

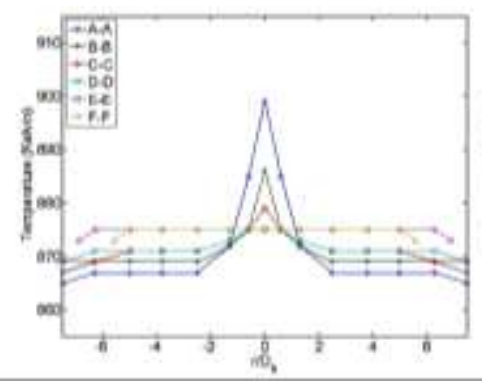

(b)

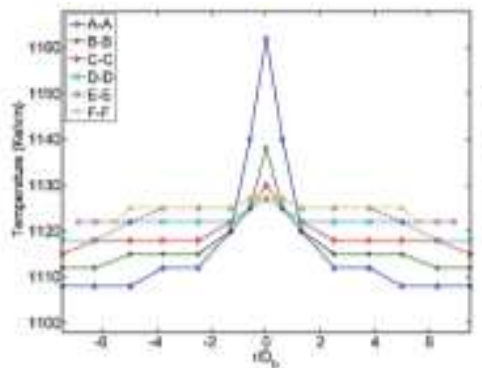

(e)

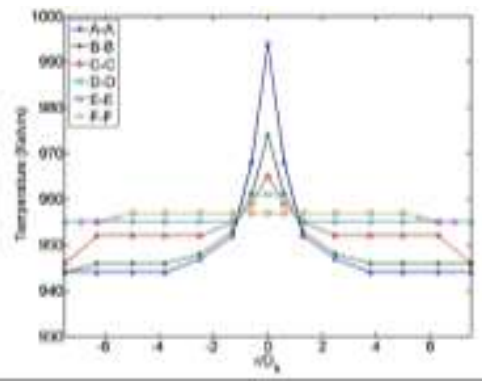

(c)

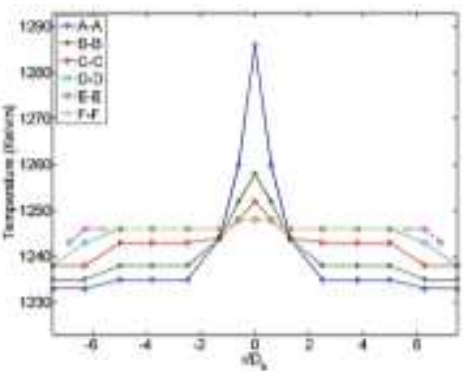

(f)

Figure 8. The temperature profile for chamber axial location of $10 \mathrm{~m} / \mathrm{s}$ air supply velocity with various oxygen mole fractions in air supply stream (lambda $=0.78$ ). (a) $3 \%$ oxygen (b) $7 \%$ oxygen (c) $9 \%$ oxygen (d) $12 \%$ oxygen (e) $15 \%$ oxygen (f) $21 \%$ oxygen.

Table 3. The oxygen mole fraction in air supply and MILD condition.

\begin{tabular}{lcccccc}
\hline \multicolumn{1}{c}{ Conditions } & \multicolumn{5}{c}{ Oxygen mole fraction $(\%)$} \\
\hline Oxygen mole fraction & 3 & 7 & 9 & 12 & 15 & 21 \\
MILD conditions & Yes & Yes & Yes & Yes & Yes & No \\
\hline
\end{tabular}

The temperature and combustion products are studied in Figures 9-12. Table 4 summarizes whether the MILD condition was achieved in Figures 9-12. Figure 9 shows the average chamber temperature where the air inlet has $7 \%$ and $21 \%$ oxygen mole fraction respectively. The atmospheric air produces higher temperatures, but the same trends appear: higher velocities and higher lambda produce higher temperatures. The temperature was drastically reduced when the fuel was reduced (lambda higher than 1.0). This is due to the combustion process was limited to lower methane supply in higher lambda cause this lower temperature. Figures 10 and 11 show that the combustion consumes all the oxygen at lower lambda, leaving excess oxygen as expected at higher lambda. The excess methane and pollutant $\mathrm{CO}$ occurred at lower lambda but not at higher since all methane consumes leaving excess oxygen. A small but significant amount of oxygen remains at lean conditions, consuming all the $\mathrm{CH}_{4}$. This greater consumption of methane produces the higher temperatures. 


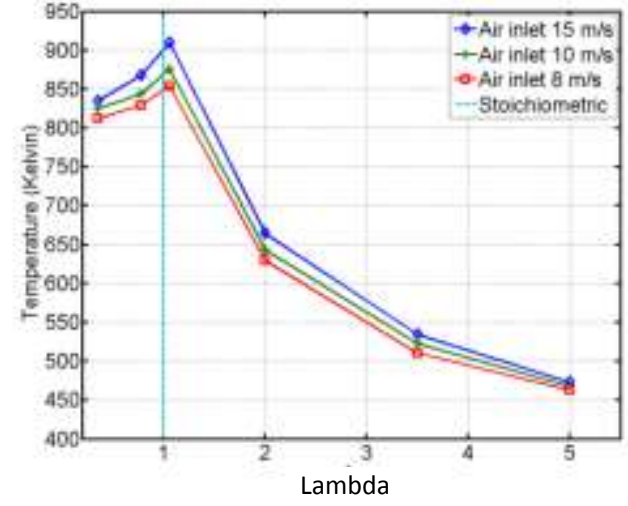

(a)

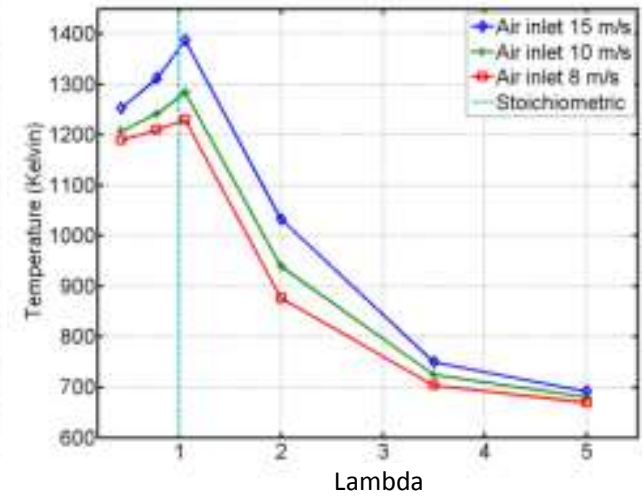

(b)

Figure 9. Chamber temperature (a) air inlet with $7 \%$ oxygen mole fraction (b) air inlet with $21 \%$ oxygen mole fraction.

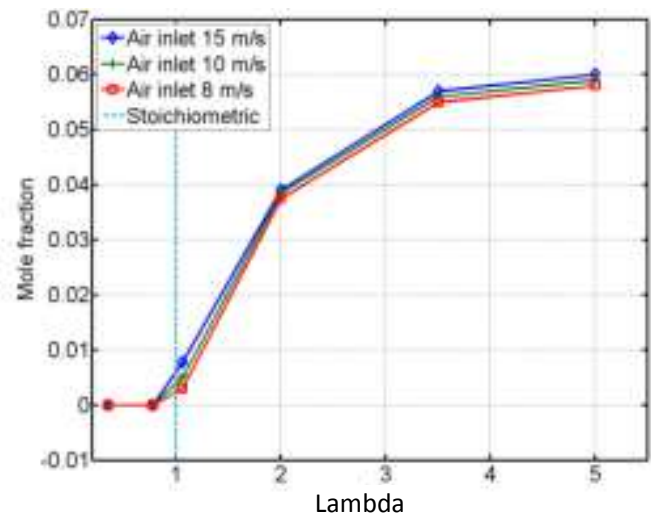

(a)

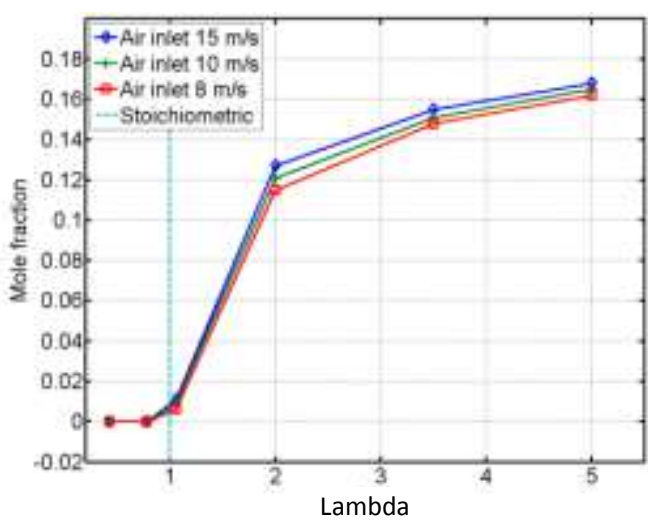

(b)

Figure 10. Excess oxygen in exhaust (a) air inlet with $7 \%$ oxygen mole fraction (b) air inlet with $21 \%$ oxygen mole fraction.

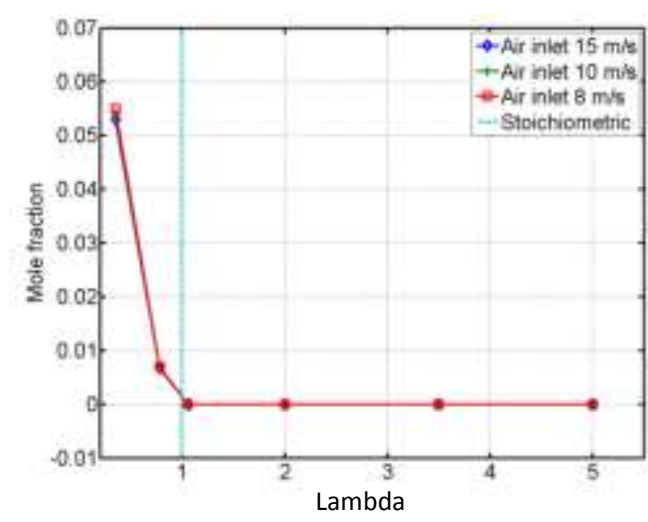

(a)

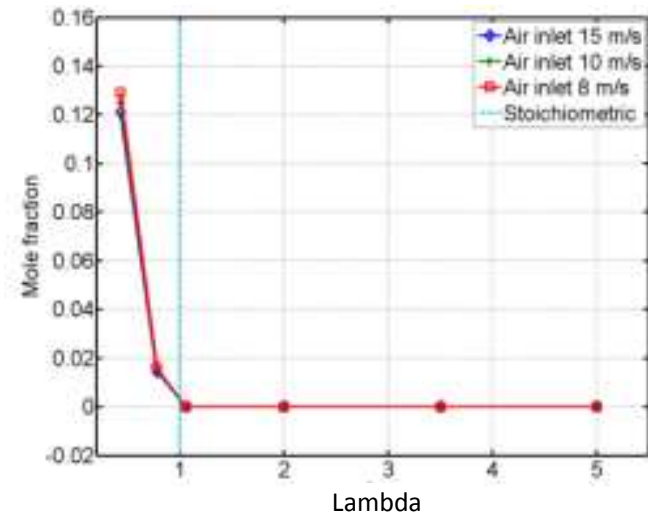

(b)

Figure 11. Unburned methane in exhaust (a) air inlet with $7 \%$ oxygen mole fraction (b) air inlet with $21 \%$ oxygen mole fraction. 


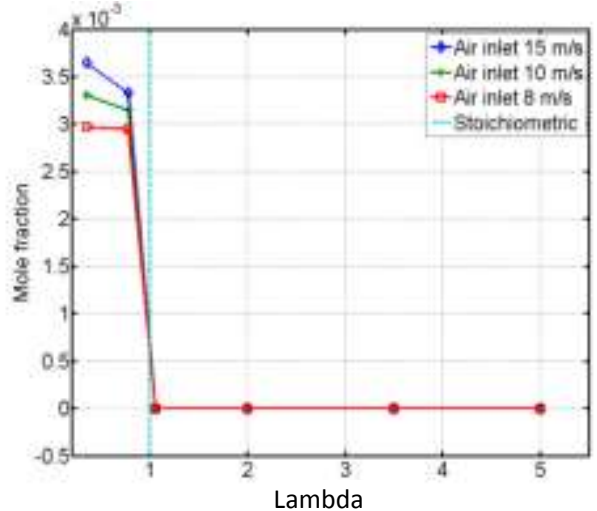

(a)

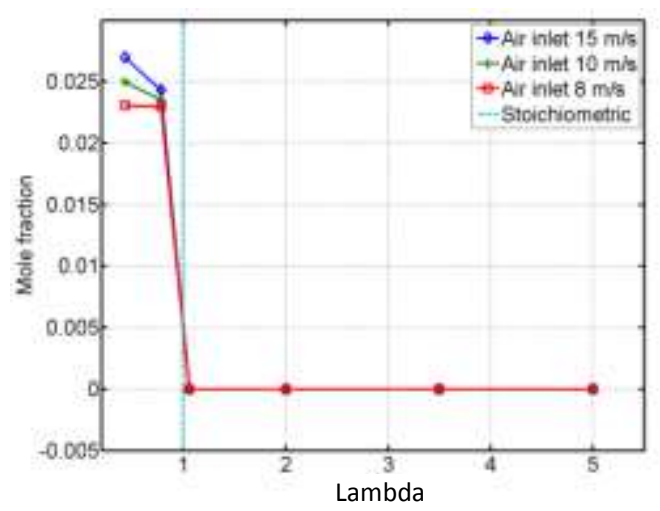

(b)

Figure 12. Pollutant carbon monoxide in exhaust (a) air inlet with $7 \%$ oxygen mole fraction (b) air inlet with $21 \%$ oxygen mole fraction.

Table 4. The oxygen mole fraction in air supply and MILD condition.

\begin{tabular}{lcc}
\hline \multicolumn{1}{c}{ Conditions } & \multicolumn{2}{c}{ Oxygen } \\
\hline Oxygen mole fraction \\
MILD condition & 7 & 21 \\
& achieved & not achieved \\
\hline
\end{tabular}

Carbon monoxide is a product of incomplete combustion due to insufficient oxygen to produce carbon dioxide. The high temperature combustion for the $21 \%$ oxygen mole fraction produces more carbon monoxide $[7,13]$ than the $7 \%$ oxygen mole fraction (Figure 12) and $\mathrm{CO}$ is only produced when there is no excess oxygen (c.f. Figure 10). More results of the study were plotted for various gases which can be seen in the Supplementary Material.

\section{CONCLUSIONS}

The flame temperature and combustion products in MILD combustion were studied numerically for varying lambda, inlet oxygen mole fraction and inlet oxygen and fuel velocity. The chemical reactions were modelled by considering chemical equilibrium based on the mixture fraction with non-adiabatic flame temperature using RANS equations and the realizable $k-\varepsilon$ turbulence model. Under lean conditions, the pollutants $\mathrm{CO}$ and UHC are effectively zero, this was proves that the proposed configuration is viable for clean combustion. The present paper concludes that:

i) The syngas that was used closely reproduced the behaviour of a real biogas, making this an attractive alternative for practical implementation in experiments.

ii) MILD conditions were found for oxygen mole fractions between $3 \%$ and 13\%, which is proven by the small variations in the chamber temperature distribution. This demonstrates that an open burner can produce MILD combustion with the utilization of EGR.

iii) The maximum chamber temperature was near stoichiometric conditions and was reduced by approximately one-third when synthetic air $\left(7 \% \mathrm{O}_{2}\right)$ was used instead of ordinary air, a consequence of the extra thermal load caused by the inert $\mathrm{N}_{2}$. 
iv) Under lean conditions, atmospheric air produced approximately $0.1 \mathrm{ppm}$ NO, while $7 \%-\mathrm{O}_{2}$ air produced zero $\mathrm{NO}$ within numerical precision. This shows that the configuration can produce negligible pollutants without the expense of separating out $\mathrm{N}_{2}$ before the combustion chamber.

\section{ACKNOWLEDGMENTS}

The authors would like to thank University of Southern Queensland (USQ) and Universiti Malaysia Pahang (UMP) for providing financial support and laboratory facilities.

\section{REFERENCES}

[1] Shafiee S, Topal E. When will fossil fuel reserves be diminished? Energy Policy. 2009;37:181-9.

[2] Yusaf T, Baker P, Hamawand I, Noor MM. Effect of compressed natural gas mixing on the engine performance and emissions. International Journal of Automotive and Mechanical Engineering. 2013;8:1416-29.

[3] Noor MM, Wandel AP, Yusaf T. Design and development of MILD combustion burner. Journal of Mechanical Engineering and Sciences. 2013;5:662-76.

[4] Noor MM, Wandel AP, Yusaf T. The simulation of biogas combustion in a mild burner. Journal of Mechanical Engineering and Sciences. 2014;6:995-1013.

[5] Gharehghani A, Hosseini R, Yusaf T. Investigation of the effect of additives to natural gas on heavy-duty si engine combustion characteristics. Journal of Mechanical Engineering and Sciences. 2013;5:677-87.

[6] Kamil M, Rahman MM, Bakar RA. Performance evaluation of external mixture formation strategy in hydrogen fueled engine. Journal of Mechanical Engineering and Sciences. 2011;1:87-98.

[7] Noor M, Wandel AP, Yusaf T. Mild combustion: the future for lean and clean combustion. International Review of Mechanical Engineering. 2013;8:251-7.

[8] Al-lwayzy S, Yusaf T. Chlorella protothecoides Microalgae as an Alternative Fuel for Tractor Diesel Engines. Energies. 2013;6:766-83.

[9] Dally BB, Shim SH, Craig RA, Ashman PJ, Szego GG. On the burning of sawdust in a MILD combustion furnace. Energy and Fuel. 2010;24:9.

[10] Cavaliere A, de Joannon M. Mild Combustion. Progress in Energy and Combustion Science. 2004;30:329-66.

[11] Noor MM, Wandel AP, Yusaf T. A review of MILD combustion and open furnace design consideration. International Journal of Automotive and Mechanical Engineering. 2012;6:730-54.

[12] Noor MM, Wandel AP, Yusaf T. Analysis of recirculation zone and ignition position of non-premixed bluff-body for biogas MILD combustion. International Journal of Automotive and Mechanical Engineering. 2013;8:1176-86.

[13] Wunning JG. Flammlose Oxidation Von Brennstoff Mit Hochvorgewarmter Luft. Chem-Ing-Tech. 1991;63:3.

[14] Mancini M, Weber R, Bollettini U. Predicting NOx emissions of a burner operated in flameless oxidation mode. Proceedings of the Combustion Institute. 2003;29:1155-63.

[15] Katsuki M, Hasegawa T. The science and technology of combustion in highly preheated air. Proceedings of Combustion Institute1998. p. 3135-46. 
[16] Tsuji H, Gupta AK, Hasegawa T. High temperature air combustion: CRC Press, Boca Raton, Forida; 2003.

[17] Arghode VK, Gupta AK, Bryden KM. High intensity colorless distributed combustion for ultra low emissions and enhanced performance. Applied Energy. 2012;92:822-30.

[18] Arghode VK, Gupta AK. Development of high intensity CDC combustor for gas turbine engines. Applied Energy. 2011;88:963-73.

[19] Dally BB, Karpetis AN, Barlow RS. Structure of turbulent non-premixed jet flames in a diluted hot coflow. Proceedings of the Combustion Institute. 2002;29:1147-56.

[20] Castela M, Veríssimo AS, Rocha AMA, Costa M. Experimental study of the combustion regimes occurring in a laboratory combustor. Combustion Science and Technology. 2012;184:16.

[21] Veríssimo AS, Rocha AMA, Costa M. Importance of the inlet air velocity on the establishment of flameless combustion in a laboratory combustor. Experimental Thermal and Fluid Science. 2013;44:75-81.

[22] Kalyani Radha K, Naga Sarada S, Rajagopal K, Nagesh EL. Performance and emission characteristics of CI engine operated on vegetable oils as alternative fuels. International Journal of Automotive and Mechanical Engineering. 2011;4:414-27.

[23] Mohanamurugan S, Sendilvelan S. Emission and combustion characteristics of different fuel In A HCCI engine. International Journal of Automotive and Mechanical Engineering. 2011;3:279-92.

[24] Smajevic I. Experimental study and computational modelling of gas-fired pulse combustion. International Journal of Automotive and Mechanical Engineering. 2010;1:1-12.

[25] Hosseini SE, Wahid MA. Biogas utilization: Experimental investigation on biogas flameless combustion in lab-scale furnace. Energy Conversion and Management. 2013;74:426-32.

[26] Colorado AF, Medwell PR, Dally BB. LCV fuels emissions of turbulent nonpremixed jet flames under MILD combustion conditions. Australian Combust Symposium. Uni. of Queensland, Australia2009.

[27] Keramiotis C, Founti MA. An experimental investigation of stability and operation of a biogas fueled porous burner. Fuel. 2013;103:278-84.

[28] Pomeroy CA. Science watch-biogas breakthrough. The Japan Journal. 2008.

[29] Noor M, Wandel AP, Yusaf T. Numerical study of oxygen dilution and temperature distribution of biogas combustion in Bluff-body MILD burner. Proceedings of the 7th Australian Combustion Symposium (ACS 2013). 2013:299-303.

[30] Kumar S, Paul PJ, Mukunda HS. Investigations of the scaling criteria for a mild combustion burner. Proceedings of the Combustion Institute. 2005;30:2613-21.

[31] Noor M, Wandel AP, Yusaf T. The modelling of the effect of air fuel ratio on unburned hydrocarbons for MILD combustion. Proceedings of the 2nd Malaysian Postgraduate Conference (MPC 2012). 2012:159-63.

[32] Noor MM, Wandel AP, Yusaf T. A review of mild combustion and open furnace design consideration. International Journal of Automotive and Mechanical Engineering. 2012;6:730-54.

[33] Galletti C, Parente A, Tognotti L. Numerical and experimental investigation of a mild combustion burner. Combustion and Flame. 2007;151:649-64. 
[34] Parente A, Galletti C, Tognotti L. Effect of the combustion model and kinetic mechanism on the MILD combustion in an industrial burner fed with hydrogen enriched fuels. International Journal of Hydrogen Energy. 2008;33:7553-64.

[35] Mardani A, Tabejamaat S, Hassanpour S. Numerical study of CO and CO2 formation in $\mathrm{CH} 4 / \mathrm{H} 2$ blended flame under MILD condition. Combustion and Flame. 2013;160:1636-49.

[36] Mardani A, Tabejamaat S, Ghamari M. Numerical study of influence of molecular diffusion in the Mild combustion regime. Combustion Theory and Modelling. 2010;14:747-74.

[37] Shih TH, Liou WW, Shabbir A, Yang Z, J. Z. A new k-e eddy-viscosity model for high Reynolds Number turbulent flows-model development and validation Computers and Fluids 1995;24:12.

[38] Chui EH, Raithby GD. Computation of radiant heat transfer on a nonorthogonal mesh using the finite-volume method. Numerical Heat Transfer, Part B: Fundamentals. 1993;23:269-88.

[39] Smith TF, Shen ZF, Friedman JN. Evaluation of Coeficients for the Weighted Sum of Gray Gases Model Journal of Heat Transfer. 1982;104:7.

[40] Lupant D, Pesenti B, Evrard P, Lybaert P. Numerical and experimental characterization of a self-regenerative flameless oxidation burner operation in a pilot-scale furnace. Combustion Science and Technology. 2007;179:437-53.

[41] Graça M, Duarte A, Coelho PJ, Costa M. Numerical simulation of a reversed flow small-scale combustor. Fuel Processing Technology. 2013;107:126-37. 